\title{
Heat Transfer Enhancement in Subchannel Geometry of Pressurized Water Reactor Using Water-Based Yttrium Oxide Nanofluid
}

\author{
Zeina Ali Abdul Redha ${ }^{1}$, Farhan Lafta Rashid ${ }^{2 *}$ \\ ${ }^{1}$ Energy Engineering Department, University of Baghdad, Baghdad 10011, Iraq \\ ${ }^{2}$ Petroleum Engineering Department, University of Kerbala, Karbala 56001, Iraq
}

Corresponding Author Email: farhan.lefta@uokerbala.edu.iq

https://doi.org/10.18280/ijht.390335

Received: 23 April 2020

Accepted: 17 March 2021

Keywords:

ANSYS fluent, CFD, PWR, subchannel geometry, water-based nanofluids

\begin{abstract}
Simulation of Computational Fluid Dynamic is applied to present the thermal performance of water-based Yttrium oxide nanofluid in subchannel of pressurized water reactor (PWR) system. Thermal hydraulic aspect such as pressure drop and heat transfer are estimated in typical conditions of pressurized water with flow rates ranged $\left(20 \times 10^{3} \leq \operatorname{Re} \leq 80 \times 10^{3}\right)$ using fresh water $(0 \%$ vol.) and different volume fraction of water-Yttrium oxide nanofluid ( 2 and $4 \%$ vol.) as coolant fluid. Results were obtained and compared with correlations of single-phase pressure drop and convective heat transfer for the case of fully developed turbulent flow. The addition of Yttrium oxide nanoparticles to the coolant fluid in pressurized water reactor led to increase in convective heat transfer coefficient and pressure drop. Increasing the nanoparticle volume fraction of (2 and $4 \%$ vol.) causing an increase in the average $\mathrm{Nu}$ by $3.46 \%$ and $7.61 \%$, respectively. The CFD model established in ANSYS software was validated by comparing the pressure drop of CFD results with Blasius correlation and $\mathrm{Nu}$ with Ma"iga et al. correlation and gave a good agreement.
\end{abstract}

\section{INTRODUCTION}

The thermal performance of coolant fluid used for cooling the fuel rod bundles (shown in Figure 1) of the pressurized water reactor is very important for the design and safe operation viewpoint. In such type of nuclear reactor, controlling of pressure and fluid temperature are of the priority for safety operation. For instance, a spot with high temperature in the cladding of fuel rod is considered as danger case. The most common nuclear reactors that use water as coolant fluid are the pressurized water reactor. The boiling point of the coolant fluid in these reactors is high due to the high-water pressure, and the fluid is always in liquid phase [1]. The important duty of the nuclear power plant is increasing the heat output from the reactor core by increasing the temperature of coolant fluid in the reactor core outlet. Some types of nanoparticles be with high thermal conductivity which be useful for enhancing heating capacity of the reactor coolant fluid. Base fluids can be replaced by nanofluid which are a good choice for improving the thermal performance of the nuclear power plant [2].

Previous studies indicate that increasing the nanoparticles concentration in the base fluid enhances both the thermal conductivity and heat transfer [2, 3]. Using nanofluid as coolant in the nuclear reactor will rises the critical heat flux, which leads to enhance the removal from nucleate boiling ratio of the coolant fluid [4-6].

Conner et al. [7] used a computational fluid dynamic scheme to simulate single-phase fluid with steady state conditions in the pressurized water reactor fuel rod assembly and achieved tests to validate the results. The numerical results were compared with the experimental and found that the computational fluid dynamic model is appropriate for estimating the behavior of coolant fluid in PWR fuel rod assembly. Kamal and Zahra [8] used silver oxide nanofluid as enhancer of a twin heat transfer and controlling the surplus reactivity in VVER-1000 which be a type of pressurized water. The coolant fluid in the first loop of this type of reactor is replaced by nanofluid to act as neutron moderator, neutron absorber, and coolant fluid. The volume fraction of $2 \%$ is found to suitable for both thermohydraulics and neutronics safety of the VVER-1000 nuclear power reactor. Abdellahoum et al. [9] performed CFD analysis for turbulent forced convection of water-based $\left(\mathrm{Cu}, \mathrm{CuO}, \mathrm{Ag}\right.$ and $\left.\mathrm{Al}_{2} \mathrm{O}_{3}\right)$ nanofluid over heated cavity in horizontal duct test section. The analysis is carried out using ANSYS software ver. 14.0 code. The increase in volume fraction of nanoparticles increases the average Nusselt number for the tested range of Reynolds number. Moghadassiet et al. [10] achieved computational fluid dynamic modeling on horizontal tube of circular cross section to study the effect of volume fraction of nanoparticles on heat transfer of laminar forced convection. They used water-based $\mathrm{Al}_{2} \mathrm{O}_{3}$ and $\mathrm{Al}_{2} \mathrm{O}_{3}-\mathrm{Cu}$ hybrid nanofluid with volume fraction of $0.1 \%$. this hybrid nanofluid gave higher convective heat transfer coefficient. Ghulam et al. [11] presented a comparative study of flow velocity, pressure, moderator temperature, fuel temperature at the fuel pin cell, and moderator density of pressurized water reactor. The thermal performance is depended on mass and enthalpy equation of the coolant/moderator with one group diffusion equation of the fuel pin. Sierchula [12] studied in separate the passive containment cooling system and passive residual heat removal system for the nuclear power plant. The outcome of this study is simulating, presenting and describing some of the most important parameters in the nuclear power plant such as reactor coolant temperature and heat transfer. Bikash Poudel 
et al. [13] performed simplified dynamic model of integral pressurized water reactor type, to estimate the supporting of the nuclear reactor to the dynamics of power plant system. This model is engaged with the modified turbine system and a resulted power system is simulated according to the processes of heat generation and heat transfer based on point kinetic and primary coolant. The responses of power system and internal reactor are when applying electrical demand of $20 \%$ electrical output with $80 \%$ of valve opening rate.

This paper presents the heat transfer enhancement in the suchannel geometry of the pressurized water reactor system using water-based Yttrium oxide nanofluid and validate the CFD results with the correlations available in the literature.

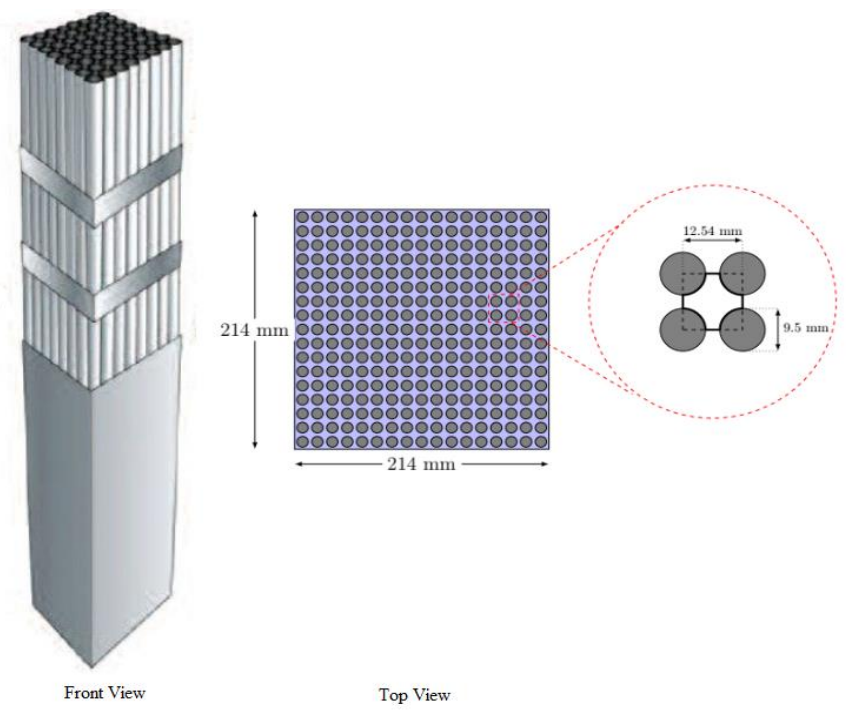

Figure 1. Front and top view of fuel rod assembly

\section{METHODOLOGY}

\subsection{Theoretical modelling}

The coolant water in the pressurized water reactor flowing in parallel to the fuel rod bundle, the unit channel is known as subchannel. Modelling this subchannel was made extensively before using the flow symmetry modelling [14-18]. FLUENT 16.0 is used to solve the steady-state Reynolds-Averaged Navier-Stokes, energy, mass, and turbulent equations. The continuity, momentum, and energy equations are listed in Eqns. (1-3) [18]:

$$
\begin{gathered}
\frac{\partial \rho u_{i}}{\partial x_{i}}=0 \\
\frac{\partial u_{i} u_{j}}{\partial x_{j}}=-\frac{\partial P}{\partial x_{i}}+\frac{\partial}{\partial x_{j}}\left[\mu\left(\frac{\partial u_{i}}{\partial x_{j}}+\frac{\partial u_{j}}{\partial x_{i}}\right)-\rho\left(u_{i}^{\prime} u_{j}^{\prime}\right)\right] \\
+\rho g_{i} \\
\frac{\partial}{\partial x_{i}}\left(u_{i}(\rho E+P)\right)=\frac{\partial}{\partial x_{i}}\left(K_{e f f} \frac{\partial T}{\partial x_{i}}+u_{j}\left(\tau_{i j}\right)_{e f f}\right)
\end{gathered}
$$

\subsection{Boundary conditions}

The coolant water enters the subchannel with uniform temperature of $293 \mathrm{~K}$ and different velocity values. The velocity of the inlet coolant water was applied with different values, which are listed in Table 1). The available correlations were chosen to validate the CFD model Reynolds number and thermal boundary conditions [19]. A relative average pressure equaling zero was defined the outlet of the computational model. The surfaces of fuel rod were assumed to be smooth. Applying constant heat flux of $584 \mathrm{KW} / \mathrm{m}^{2}$ on the outer fuel rod surface. Bianco et al. formula [15, 20-22] based on thermophysical properties of the nanofluid with different volume fractions of 2 and $4 \%$ vol. at room temperature has been chosen to estimate the Reynolds number $(\operatorname{Re}=$ $(\rho \cdot v \cdot D h) / \mu)$. Assumption of this work can be summarized as: steady state condition, constant heat flux, incompressible fluid, Newtonian fluid, and turbulent flow.

Table 1. Inlet velocities (m/s) and Reynolds numbers

\begin{tabular}{cccc}
\hline $\operatorname{Re}$ & $\varphi=0$ & $\varphi=2 \%$ & $\varphi=4 \%$ \\
\hline $20 \times 10^{3}$ & 6.57 & 7.26 & 8.43 \\
$40 \times 10^{3}$ & 13.13 & 14.52 & 16.86 \\
$60 \times 10^{3}$ & 19.70 & 21.75 & 25.28 \\
$80 \times 10^{3}$ & 26.26 & 29.04 & 33.71 \\
\hline
\end{tabular}

\subsection{Thermo-physical properties of nanofluids}

In practical applications, nanofluids contain the oxide particles with finer size up to $40 \mathrm{~nm}$ [15]. In the present work the used nanofluids is water contained nanoparticles of $\mathrm{Y}_{2} \mathrm{O}_{3}$ with mean particle size of $40 \mathrm{~nm}$. In order to estimate the density, heat capacity, dynamic viscosity, and thermal conductivity of water-based nanofluids, it will be needed to use the following equations [14, 20-24],

$$
\begin{gathered}
\rho_{n f}=(1-\varphi) \rho_{b f}+\varphi \rho_{p} \\
\left(c_{p}\right)_{n f}=(1-\varphi)\left(c_{p}\right)_{b f}+\varphi\left(c_{p}\right)_{p} \\
\mu_{n f}=\left(123 \varphi^{2}+7.3 \varphi+1\right) \mu_{b f} \\
k_{n f}=\left(4.97 \varphi^{2}+2.72 \varphi+1\right) K_{b f}
\end{gathered}
$$

The thermophysical properties of water-based nanofluid and $\mathrm{Y}_{2} \mathrm{O}_{3}$ nanoparticle are listed in Tables 2 and 3, respectively.

Table 2. Thermophysical properties of nanofluid with different nanoparticle volume fractions at $293 \mathrm{~K}$

\begin{tabular}{ccccc}
\hline$\varphi(\%)$ & $\rho\left(\mathrm{kg} / \mathrm{m}^{3}\right)$ & $c_{p}(\mathrm{~J} / \mathrm{kg} . \mathrm{K})$ & $k(\mathrm{~W} / \mathrm{m} . \mathrm{K})$ & $\mu(\mathrm{Pa} . \mathrm{s})$ \\
\hline 0 & 1000 & 4182 & 0.597 & 0.000998 \\
2 & 1080 & 4107 & 12.677 & 0.001192 \\
4 & 1160 & 4032 & 13.401 & 0.001486 \\
\hline
\end{tabular}

Table 3. $\mathrm{Y}_{2} \mathrm{O}_{3}$ nanoparticle at $293 \mathrm{~K}$

\begin{tabular}{ccc}
\hline$\rho\left(\mathrm{kg} / \mathrm{m}^{3}\right)$ & $c_{p}(\mathrm{~J} / \mathrm{kg} . \mathrm{K})$ & $k(\mathrm{~W} / \mathrm{m} . \mathrm{K})$ \\
\hline 5000 & 440 & 12 \\
\hline
\end{tabular}

\subsection{Grid independency study}

The influence of mesh size on the sensitivity of results must be studied for the first step of accomplishing a CFD simulation. For more accurate approach, a more nodes are needed, and using further nodes will escalates the requisite computational time and computer memory. In order to determining the suitable number of nodes, it can be done by increasing the 
nodes number until the mesh being fine. Figure 2 presents the temperature variation with grid cell number for $4 \%$ vol. and $\mathrm{Re}=80 \times 10^{3}$. It was shown that the increase in cell number increases temperature until reaching to approximately constant value.

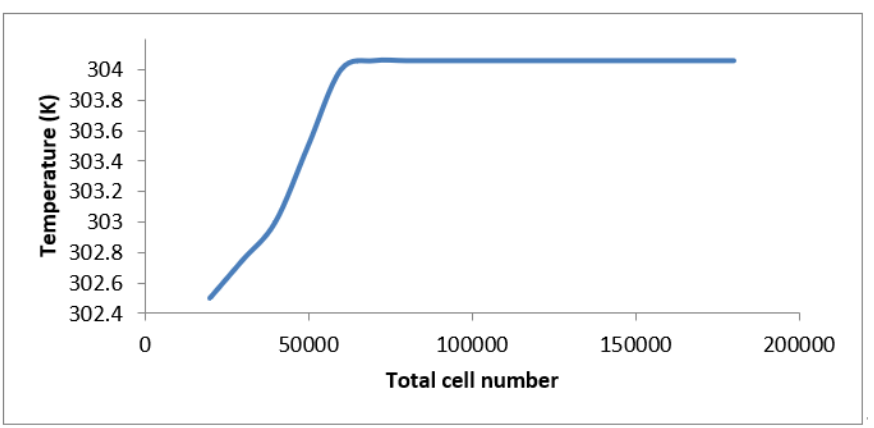

Figure 2. Grid independency study for temperature of $4 \%$ vol. and $\operatorname{Re}=80 \times 10^{3}$

\subsection{Convergence}

A solution was converged when all conservation differential equations (continuity equation, $\mathrm{X}$-velocity, Y-velocity, Zvelocity, energy equation, and $\boldsymbol{k}-\boldsymbol{\varepsilon}$ ) were subjected to a specified tolerance at all points. Therefore, the monitoring the convergence of the solution was very important. Figure 3 shows convergence of volumetric flow rate at the outlet. It can be seen that the convergence occur at 200 iterations.

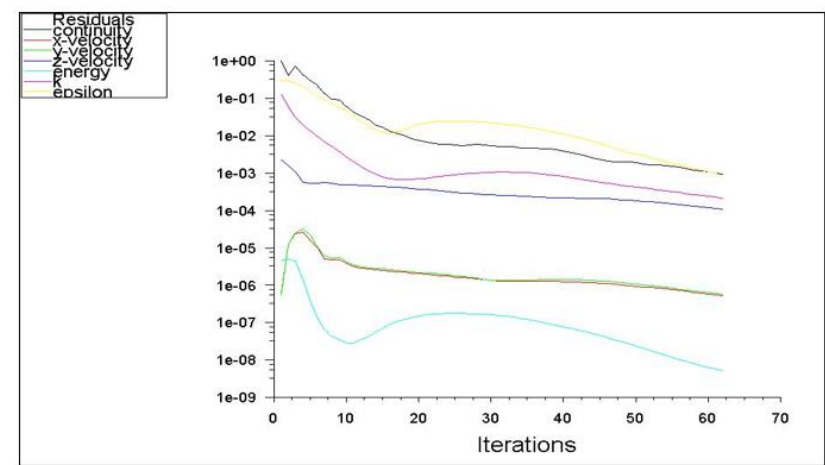

Figure 3. Convergence of iterations

\section{RESULTS AND DISCUSSION}

The CFD results are obtained and evaluated in terms of average heat transfer coefficient, Nusselt number, and pressure drop for the inlet coolant flow velocity corresponding to Reynolds number of $20 \times 10^{3}, 40 \times 10^{3}, 60 \times 10^{3}$, and $80 \times 10^{3}$, with $\mathrm{Y}_{2} \mathrm{O}_{3}$ volume fraction of 0,2 , and $4 \%$. The single-phase approach with constant heat flux of $584 \mathrm{~W} / \mathrm{m}^{2}$ is used to obtain the results. In all cases the particles size was considered equal to $40 \mathrm{~nm}$.

The validation of the water-based $\mathrm{Y}_{2} \mathrm{O}_{3}$ nanofluids has been achieved using the correlations in the literature and considering a fully developed turbulent flow as a function of average Nusselt number and pressure losses for smooth wall pipe. The widely used correlation suggested by Maïga et al. [15] (8) is used to validate the average Nusselt number:

$$
N u=0.085 \operatorname{Re}^{0.71} \mathrm{Pr}^{0.35}
$$

$$
\begin{gathered}
10^{4} \leq R e \leq 5 \times 10^{5} \\
6.6 \leq \operatorname{Pr} \leq 13.9 \\
0 \leq \varphi \leq 10 \%
\end{gathered}
$$

Correlation of Eq. (8) is used to calculate the heat transfer coefficient for the water-based $\mathrm{Y}_{2} \mathrm{O}_{3}$ nanofluid flowing in smooth tube under the condition of constant heat flux.

\subsection{Velocity profile}

The velocity profile along the center of coolant fluid passing through the suchannel of 5\% vol. is presented in Figure 4 . It is noted that, the non-dimensional centerline velocity $(V / V \mathrm{in})$ increases as Reynolds number decrease, and decreases with non-dimensional flowing distance $(Z / L)$.

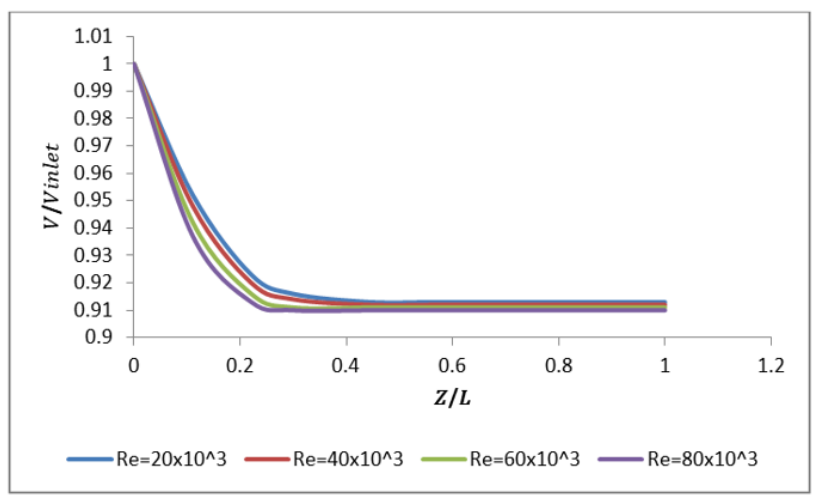

Figure 4. Velocity distribution at different locations for $4 \%$ vol. nanofluid

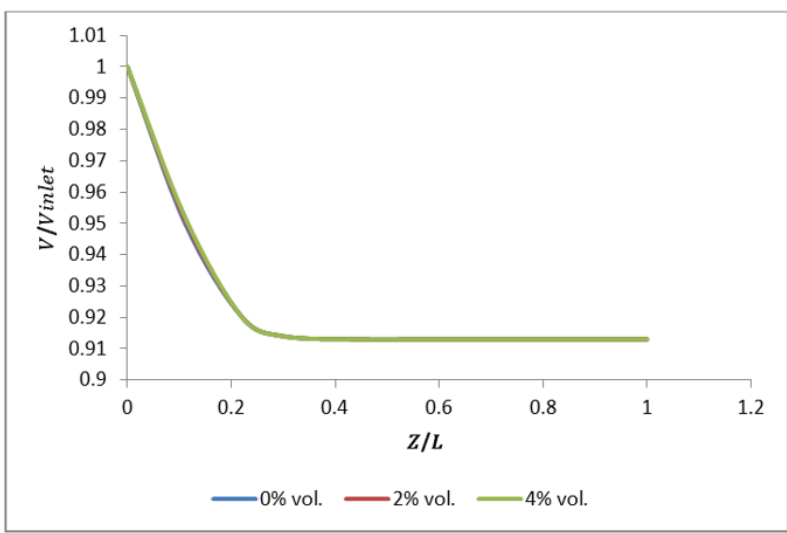

Figure 5. Velocity distribution for different $\%$ vol. and $\mathrm{Re}=80 \times 10^{3}$
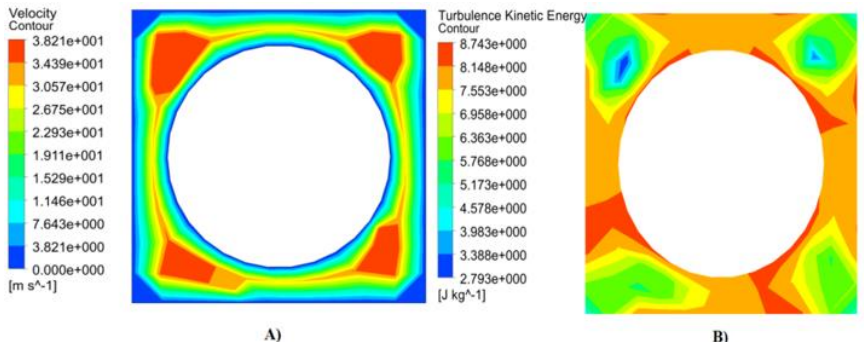

Figure 6. A) local velocity and B) turbulent kinetic energy at the coolant water outlet for $\mathrm{Re}=80 \times 10^{3}$ and $4 \% \mathrm{vol}$

The effect of varying the volume fraction of nanoparticles ( $\varphi=0 \%, 1 \%$ and $4 \%$ vol.) on the velocity distribution along 
the centerline of water-based $\mathrm{Y}_{2} \mathrm{O}_{3}$ nanofluid with constant Reynolds number $\left(\mathrm{Re}=80 \times 10^{3}\right)$ is presented in Figure 5. It is clear that the increase in volume fraction of $\mathrm{Y}_{2} \mathrm{O}_{3}$ nanoparticles does not affect the velocity magnitude in accordance with $[15,19]$. The velocity and turbulent kinetic energy contours at the subchannel outlet for nanoparticle volume fraction of $4 \%$ and $\mathrm{Re}=80 \times 10^{3}$ are presented in Figure 6.

\subsection{Temperature profile}

Contours of temperature profile at the subchannel outlet for different particle volume fractions $(0,2$, and $4 \%$ vol.) are shown in Figure 7 A, B, and C, respectively. It is clear that the presence of nanoparticles in coolant fluid has an advantageous effect on the bulk and wall temperatures compared to the case of fresh coolant water.

The temperature profile along the coolant fluid centerline with different nanoparticle volume fraction is shown in Figure 8. It is clear that temperature profile of coolant water increases for all values of nanoparticle volume fractions. The coolant water absorbs heat along moving through the subchannel. The bulk temperature of fresh water seems to be larger than the case of $2 \%$ and $4 \%$ volume fraction. The presence of nanoparticles make constant heat flux along the fuel rod wall for all value of volume fractions, and thus lead to decrease the temperature profile with increasing nanoparticle volume fraction.
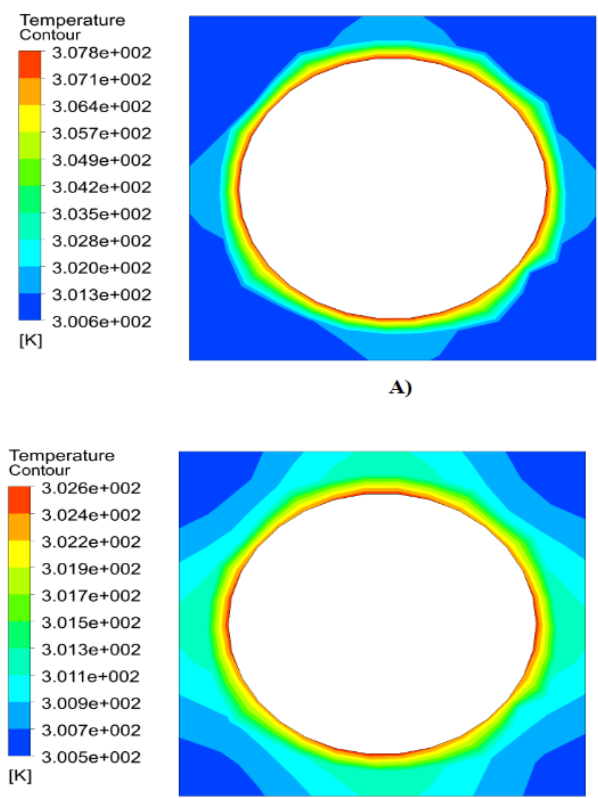

B)
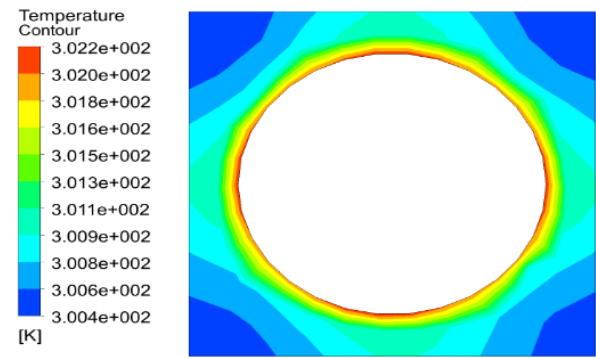

C)

Figure 7. Contour of local temperature at the channel outlet for $\left.\mathrm{Re}=80 \times 10^{3}, \mathrm{~A}\right) 0 \%$, B) $2 \%$, and C) $4 \% \mathrm{vol}$

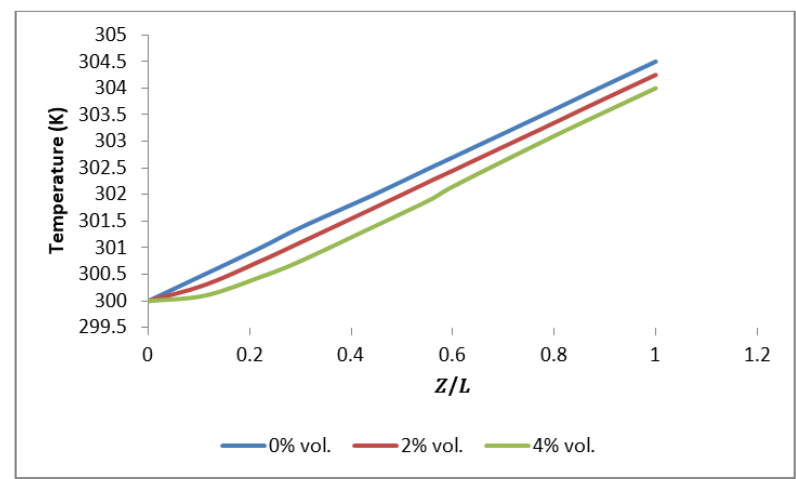

Figure 8. Temperature distribution along the channel centerline and $\mathrm{Re}=80 \times 10^{3}$

\subsection{Pressure drop}

The efficiency of nanofluid application can be determined by the coolant fluid pressure drop in heated subchannel. The coolant fluid pumping power and pressure drop are carefully concerned. The pressure profile in the coolant fluid with different flow Reynolds number and nanoparticle volume fraction is described in Figure 9. The pressure drop seems to be increased with increasing Reynolds number for all volume fractions and that the pressure drop of nanofluids increases with the increasing volume fractions as shown in Figure 10. This may attribute to due to the fact that the coolant pressure drop could influenced by the viscosity and density of coolant fluid.

The Moody chart or other available correlation can be used to determine the friction factor of the subchannel geometry. The friction factor of single-phase turbulent flow Reynolds number $2300<\operatorname{Re}<100 \times 103$ for smooth pipe can be calculated by the Blasius correlation:

$$
f=\frac{0.3164}{R e^{0.25}}
$$

The drop in pressure caused by friction can be estimated by:

$$
\Delta P=f\left(\frac{L}{2 D_{h}}\right) \rho v^{2}
$$

Eq. (11) can be used to find the effect of nanoparticle in coolant fluid, this achieved by the difference in pressure drop along the coolant fluid in subchannel and compared with base (fresh) fluid.

$$
d P=\left(\frac{\Delta P_{n f}-\Delta P_{b f}}{\Delta P_{b f}}\right) x 100(\%)
$$

Table 4. Difference in pressure drop between 2 and $0 \%$ vol

\begin{tabular}{cccc}
\hline $\operatorname{Re}$ & $\begin{array}{c}\Delta P(P a) \\
\text { present work } \\
(0 \% \text { vol. })\end{array}$ & $\begin{array}{c}\Delta P(P a) \\
\text { present work } \\
(2 \% \text { vol. })\end{array}$ & $\begin{array}{c}\text { Difference in } \\
\text { pressure drop } \\
(\%)\end{array}$ \\
\hline $20 \times 10^{3}$ & 1000 & 1150 & 15 \\
$40 \times 10^{3}$ & 6000 & 7020 & 17 \\
$60 \times 10^{3}$ & 16000 & 18880 & 18 \\
$80 \times 10^{3}$ & 26000 & 30950 & 19 \\
\hline
\end{tabular}

The result reveals that the $\mathrm{Y}_{2} \mathrm{O}_{3} /$ water pressure drop make maximum increases by about $19 \%$ and $94 \%$ for $\varphi=2 \%$ and $\varphi=4 \%$ 
of, respectively as shown in Tables 4 and 5 .

Table 5. Difference in pressure drop between 4 and $0 \%$ vol

\begin{tabular}{cccc}
\hline $\operatorname{Re}$ & $\begin{array}{c}\Delta P(P a) \\
\text { present work } \\
(0 \% \text { vol. })\end{array}$ & $\begin{array}{c}\Delta P(P a) \\
\text { present work } \\
(4 \% \text { vol. })\end{array}$ & $\begin{array}{c}\text { Difference in } \\
\text { pressure drop } \\
(\%)\end{array}$ \\
\hline $20 \times 10^{3}$ & 1000 & 1900 & 90 \\
$40 \times 10^{3}$ & 6000 & 11520 & 92 \\
$60 \times 10^{3}$ & 16000 & 31040 & 94 \\
$80 \times 10^{3}$ & 26000 & 50440 & 94 \\
\hline
\end{tabular}

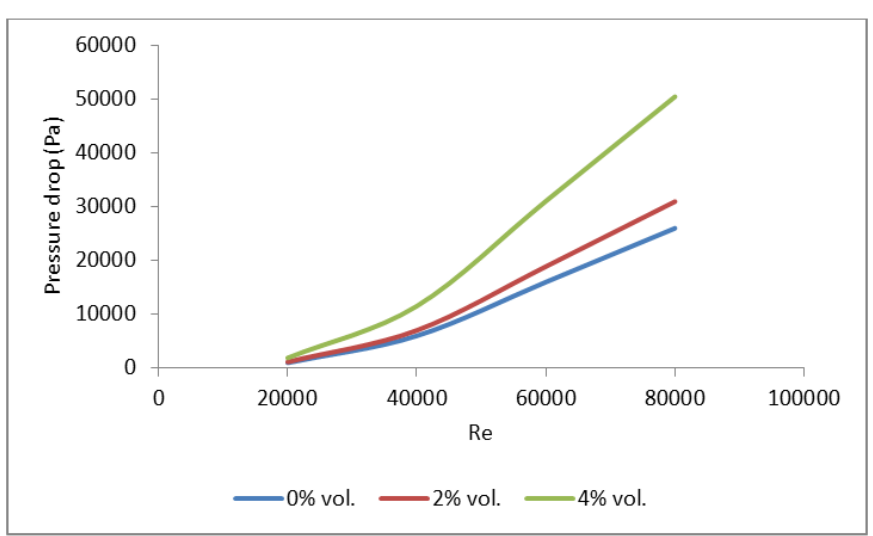

Figure 9. Pressure drop vs. Re for different \%vol
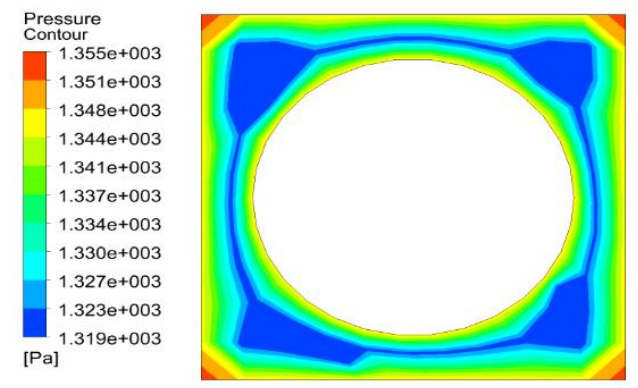

A)
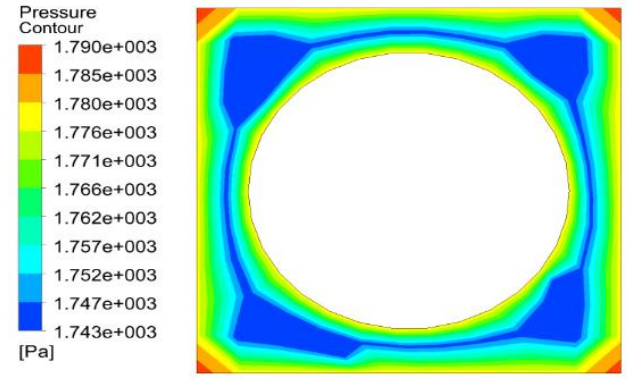

B)
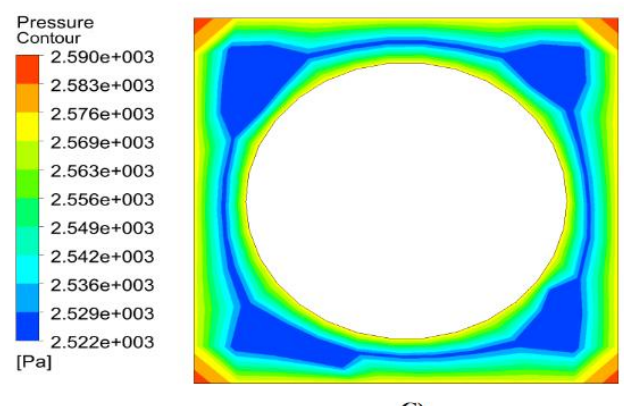

C)

Figure 10. Contour of local pressure at the channel outlet for $\left.\mathrm{Re}=80 \times 10^{3}, \mathrm{~A}\right) 0 \%$, B) $2 \%$, and C) $4 \%$ vol

\subsection{Calculations of heat transfer}

Heat transfer calculations can be made by applying a constant heat flux to the fuel rod walls along the subchannel and constant temperature at the subchannel inlet for different nanoparticle volume fraction. The local and average heat transfer coefficients are defined as follows:

$$
h(z)=\frac{Q}{A\left(T(z)_{W}-T(z)_{b}\right)}
$$

$$
\begin{array}{r}
q=\text { heat } f l u x=\frac{Q}{A}, \text { thus } \\
\qquad \begin{aligned}
h(z) & =\frac{q}{T(z)_{W}-T(z)_{b}} \\
h_{a v} & =\frac{1}{L} \int_{0}^{L} h(z) d z
\end{aligned}
\end{array}
$$

Calculations of Nusselt number was done by averaging heat transfer coefficient values over the wall region surface, and listed in Table 6 . The equation of average Nusselt number is estimated from the following equation:

$$
N u=\frac{h_{a v} \cdot D}{K_{0}}
$$

Figure 11 presents the average heat transfer coefficient for different nanoparticle volume fraction and flow Reynolds number. The heat transfer provided by the inclusion of nanoparticles in comparison with the case of fresh fluid is the useful contribution. The value of heat transfer coefficient is increases with increasing flow Reynolds number and nanoparticle volume fraction. The cause of this increase is from the fact that the improving of thermophysical properties of the nanofluid with respect to the fresh fluid. The fluid with high thermal conductivity of nanoparticles will have higher heat transfer. So, nanoparticles will increase the fluid density, thus it is required to increase the bulk temperature if compared with the case of fresh fluid. Increase the difference in temperature between wall and bulk will excite the increase in the heat transfer coefficient.

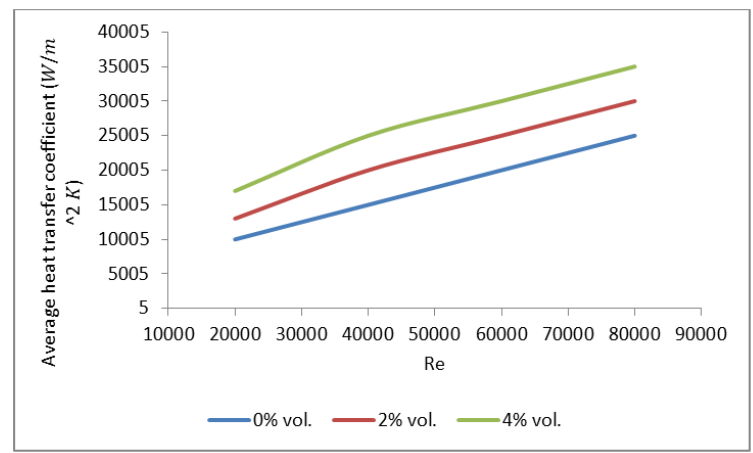

Figure 11. Average heat transfer coefficient for different \%vol. and Re

Figure 12 shows the variation of the averaged Nusselt number for all volume fraction and Reynolds number. It is clear that average Nusselt number increases with increasing volume fraction by $3.46 \%$ for the $2 \%$ vol. and $7.61 \%$ for $4 \%$ vol. 
Table 6. Average Nu for different \%vol. and Re

\begin{tabular}{cccc}
\hline Reynolds number & 0\% Vol. & 2\% Vol. & $\mathbf{4 \%}$ Vol. \\
\hline 20x10 & 162 & 174 & 189 \\
$40 \times 10^{3}$ & 287 & 299 & 315 \\
$60 \times 10^{3}$ & 412 & 424 & 440 \\
$80 \times 10^{3}$ & 537 & 549 & 573 \\
\hline
\end{tabular}

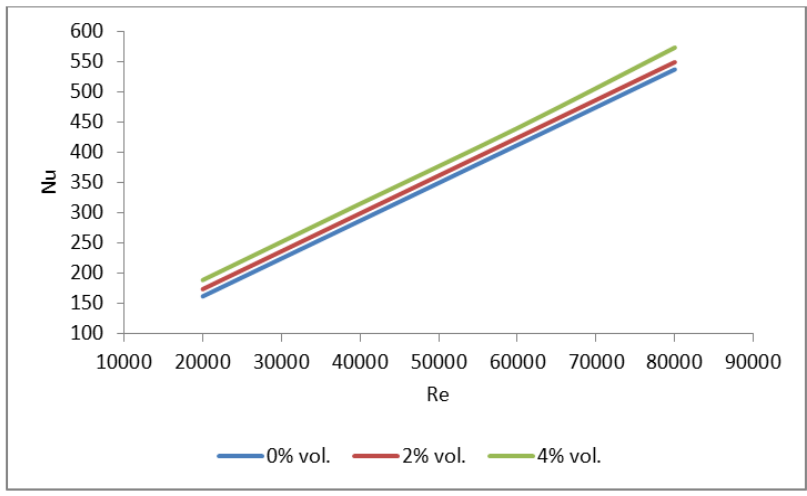

Figure 12. Average $\mathrm{Nu}$ for different $\%$ vol. and Re

\subsection{Validation of the CFD results}

The CFD Results estimated by ANSYS Fluent were validated by comparing the pressure drop with Blasius correlation and $\mathrm{Nu}$ with Maïga et al. [15]. Figures 13, 14, and 15 show the pressure drop-Re results of 0,2 , and $4 \%$ vol., respectively with the experimental correlations proposed by Blasius. The CFD results for the pressure drop show a maximum deviation of $\pm 3.58, \pm 13.42$, and $\pm 11.56 \%$ for 0,2 , and $4 \%$ vol., respectively from the correlation.

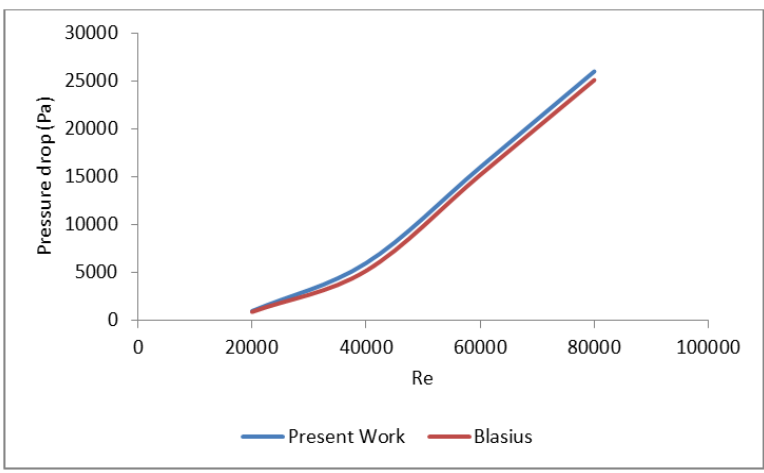

Figure 13. Comparison of pressure drop with Blasius correlation for $0 \% \mathrm{vol}$

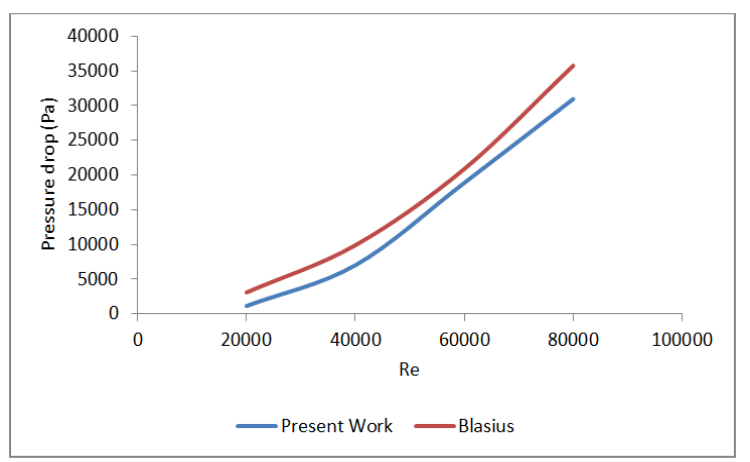

Figure 14. Comparison of pressure drop with Blasius correlation for $2 \%$ vol

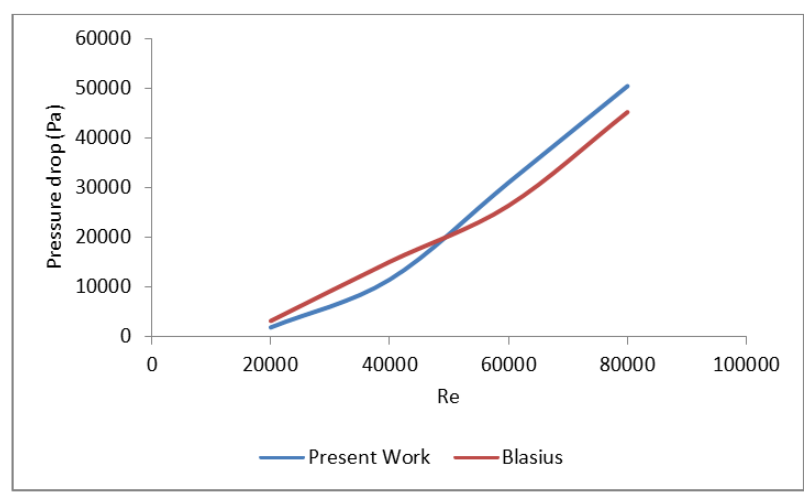

Figure 15. Comparison of pressure drop with the Blasius correlation for $4 \% \mathrm{vol}$

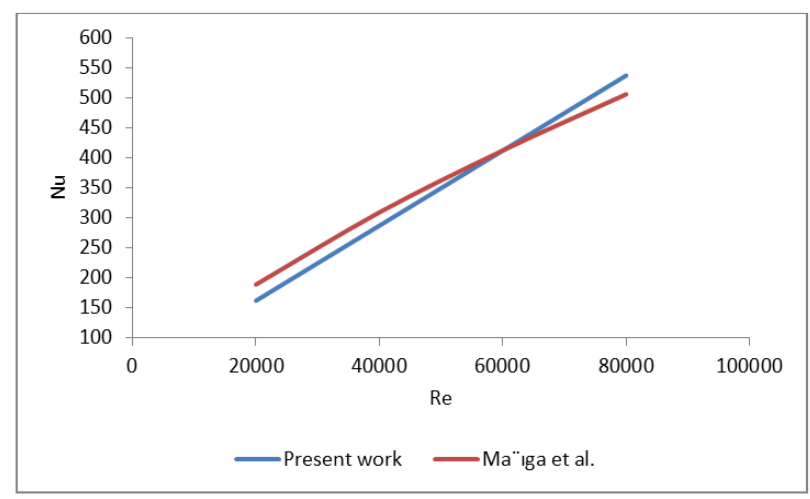

Figure 16. Comparison of average $\mathrm{Nu}$ with the correlations for pure water

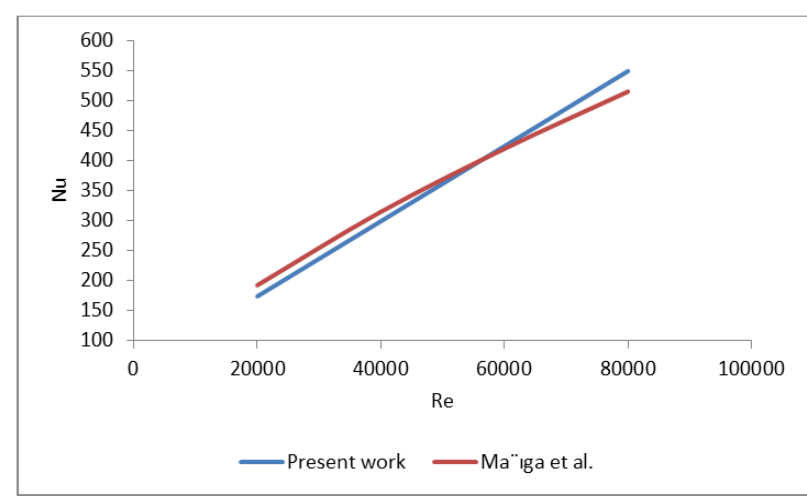

Figure 17. Comparison of average $\mathrm{Nu}$ with the correlations for $2 \% \mathrm{vol}$

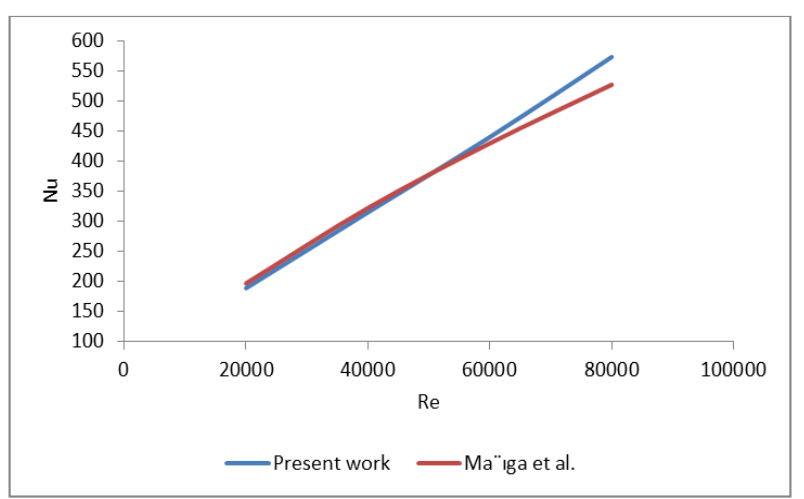

Figure 18. Comparison of average $\mathrm{Nu}$ with the correlations for $4 \% \mathrm{vol}$ 
Figures 16,17 , and 18 show the $\mathrm{Nu}-\mathrm{Re}$ results of 0,2 , and $4 \%$ vol., respectively with the experimental correlations proposed by Maïga et al. [15]. The CFD results for the $\mathrm{Nu}$ show a maximum deviation of $\pm 6.18, \pm 6.64$, and $\pm 8.74 \%$ for 0,2 , and $4 \%$ vol., respectively from the correlation.

\section{CONCLUSIONS}

Thermal analysis of heat transfer enhancement in subchannel geometry of pressurized water reactor using waterbased Yttrium oxide nanofluid under steady-state turbulent flow condition, single phase, incompressible, and uniform heat flux. The CFD results are validated with the correlations in the literature and the conclusion can be listed as follows:

1. Using Yttrium oxide nanoparticles in the base fluid has an important duty in increasing the heat transfer rate. Although, the presence of nanoparticles in the coolant fluid increases the pressure drop if compared with the fresh fluid.

2. The increase in volume fraction of nanoparticles increases the heat transfer coefficient. As example, by increasing the volume fraction of nanoparticles from 0 to $2 \%$, the heat transfer coefficient enhances by $20 \%$.

3. The total pressure drop was raised gradually by increasing the volume fraction of nanoparticles. As example, by increasing the volume fraction of nanoparticles from 0 to $2 \%, 0$ to $4 \%$ the total pressure drop increases by $19 \%$ and $94 \%$, respectively.

4. The CFD results for the pressure drop show a maximum deviation of $\pm 3.58, \pm 13.42$, and $\pm 11.56 \%$ for 0,2 , and $4 \%$ vol., respectively from the correlation. The CFD results for the $\mathrm{Nu}$ show a maximum deviation of $\pm 6.18, \pm 6.64$, and $\pm 8.74 \%$ for 0,2 , and $4 \%$ vol., respectively from the correlation.

\section{ACKNOWLEDGMENT}

The authors would like to thank encouragement and assistance from their university, families, colleagues, friends, and tutors.

\section{REFERENCES}

[1] Jalili, P.S., Rahimi, S.A., Mohammadyari, R., Rahimi, E.M. (2015). Thermo-hydraulic investigation of nanofluid as a coolant in VVER-440 fuel rod bundle. Trans. Phenom. Nano Micro Scales, 3(2): 77-88. https://doi.org/10.7508/tpnms.2015.02.002

[2] Chen, Y.J., Li, Y.Y., Liu, Z.H. (2014). Numerical simulations of forced convection heat transfer and flow characteristics of nanofluids in small tubes using twophase models. International Journal of Heat and Mass Transfer, 78: 993-1003. https://doi.org/10.1016/j.ijheatmasstransfer.2014.07.052

[3] Togun, H., Abu-Mulaweh, H.I., Kazi, S.N., Badarudin, A. (2016). Numerical simulation of heat transfer and separation $\mathrm{Al}_{2} \mathrm{O}_{3}$ /nanofluid flow in concentric annular pipe. International Communications in Heat and Mass Transfer, 71 :

108-117. https://doi.org/10.1016/j.icheatmasstransfer.2015.12.01
4

[4] Nayak, A.K., Kulkarni, P.P., Chinchole, A.S. (2015). Experimental investigation on pool boiling critical heat flux with nanofluids. Journal of Nanofluids, 4(2): 140146. https://doi.org/10.1166/jon.2015.1145

[5] Vassallo, P., Kumar, R., D’Amico, S. (2004). Pool boiling heat transfer experiments in silica-water nanofluids. International Journal of Heat and Mass Transfer, 47(2): $\quad 407-411 . \quad \mathrm{https} / / /$ doi.org/10.1016/S00179310(03)00361-2

[6] You, S. M., Kim, J.H., Kim, K.H. (2003). Effect of nanoparticles on critical heat flux of water in pool boiling heat transfer. Applied Physics Letters, 83(16): 33743376. https://doi.org/10.1063/1.1619206

[7] Conner, M.E., Baglietto, E., Elmahdi, A.M. (2010). CFD methodology and validation for single-phase flow in PWR fuel assemblies. Nuclear Engineering and Design, 240(9): 2088-2095 https://doi.org/10.1016/j.nucengdes.2009.11.031

[8] Hadad, K., Kowsar, Z. (2015). Application of nanofluids as the primary coolant and neutron absorber in a PWR reactor. International Conference on Emerging Nuclear Energy Sciences, Istanbul-Turkey, pp. 1-9.

[9] Abdellahoum, C., Mataoui, A., Oztop, H.F. (2015). Turbulent forced convection of nanofluid over a heated shallow cavity in a duct. Powder Technology, 277: 126134. https://doi.org/10.1016/j.powtec.2015.02.048

[10] Moghadassi, A., Ghomi, E., Parvizian, F. (2015). A numerical study of water based $\mathrm{Al}_{2} \mathrm{O}_{3}$ and $\mathrm{Al}_{2} \mathrm{O}_{3}-\mathrm{Cu}$ hybrid nanofluid effect on forced convective heat transfer. International Journal of Thermal Sciences, 92: 50-57. https://doi.org/10.1016/j.ijthermalsci.2015.01.025

[11] Zakir, M.G., Sarkar, M.R., Hossain, A. (2019). Analysis of Neutronics and Thermal-Hydraulic Behavior in a Fuel Pin of Pressurized Water Reactor (PWR). World Journal of Nuclear Science and Technology, 9(2): 74-83. https://doi.org/10.1016/10.4236/wjnst.2019.92005

[12] Sierchuła, J. (2019). Analysis of passive residual heat removal system in AP1000 nuclear power plant. In IOP Conference Series: Earth and Environmental Science, 214(1): $\quad 012095 . \quad$ https://doi.org/10.1088/1755$1315 / 214 / 1 / 012095$

[13] Poudel, B., Joshi, K., Gokaraju, R. (2019). A Dynamic Model of Small Modular Reactor Based Nuclear Plant for Power System Studies. IEEE Transactions on Energy Conversion, 35(2): 977-985. https://doi.org/10.1109/TEC.2019.2956707

[14] Nazififard, M., Nematollahi, M., Suh, K.Y. (2011). Numerical analysis of water-based nanofluid coolant for small modular reactor. In Small Modular Reactors Symposium, 54730: 199-205. https://doi.org/10.1115/SMR2011-6662

[15] Maïga, S.E.B., Nguyen, C.T., Galanis, N., Roy, G., Maré, T., Coqueux, M. (2006). Heat transfer enhancement in turbulent tube flow using $\mathrm{Al}_{2} \mathrm{O}_{3}$ nanoparticle suspension. International Journal of Numerical Methods for Heat \& Fluid Flow, 16(3): 275-292. https://doi.org/10.1108/09615530610649717

[16] Nazififard, M., Nematollahi, M., Jafarpur, K., Suh, K.Y. (2012). Computational analysis for research reactor IR40 rod bundle. Atw. Internationale Zeitschrift fuer Kernenergie, 57(8-9): 523-529.

[17] Nematollahi, M.R., Nazifi, M. (2008). Enhancement of 
heat transfer in a typical pressurized water reactor by different mixing vanes on spacer grids. Energy Conversion and Management, 49(7): 1981-1988. https://doi.org/10.1016/j.enconman.2007.12.016

[18] Liu, C.C., Ferng, Y.M. (2010). Numerically simulating the thermal-hydraulic characteristics within the fuel rod bundle using CFD methodology. Nuclear Engineering and Design, 240(10): 3078-3086. https://doi.org/10.1016/j.nucengdes.2010.05.021

[19] Pak, B.C., Cho, Y.I. (1998). Hydrodynamic and heat transfer study of dispersed fluids with submicron metallic oxide particles. Experimental Heat Transfer an International Journal, 11(2): 151-170. https://doi.org/10.1080/08916159808946559

[20] Bianco, V., Chiacchio, F., Manca, O., Nardini, S. (2009). Numerical investigation of nanofluids forced convection in circular tubes. Applied Thermal Engineering, 29(1718): 3632-3642. https://doi.org/10.1016/j.applthermaleng.2009.06.019

[21] Bianco, V., Manca, O., Nardini, S. (2011). Numerical investigation on nanofluids turbulent convection heat transfer inside a circular tube. International Journal of Thermal Sciences, 50(3): 341-349. https://doi.org/10.1016/j.ijthermalsci.2010.03.008

[22] Bianco, V., Manca, O., Nardini, S. (2010). Numerical simulation of water $/ \mathrm{Al}_{2} \mathrm{O}_{3}$ nanofluid turbulent convection. Advances in Mechanical Engineering, 2: 976254. https://doi.org/10.1155/2010/976254

[23] Bianco, V., Nardini, S., Manca, O. (2011). Enhancement of heat transfer and entropy generation analysis of nanofluids turbulent convection flow in square section tubes. Nanoscale Research Letters, 6(1): 1-12. https://doi.org/10.1186/1556-276X-6-252

[24] Nazififard, M., Nematollahi, M., Jafarpour, K., Suh, K.Y. (2012). Augmented safety heat transport in research reactor IR-40 using nanofluid. Atw. Internationale Zeitschrift Fuer Kernenergie, 57(4): 262-270.

\section{NOMENCLATURE}

$C_{p} \quad$ Specific heat $(\mathrm{J} / \mathrm{kgK})$

D Diameter $(\mathrm{m})$

$D_{h} \quad$ Equivalent hydraulic diameter (m)

f Friction factor (....)

g Acceleration of gravity $\left(\mathrm{m} / \mathrm{s}^{2}\right)$

$\mathrm{h} \quad$ Heat transfer coefficient $\left(\mathrm{W} / \mathrm{m}^{2} \mathrm{~K}\right)$

$\mathrm{k}$ Thermal conductivity (W/m K)

$\mathrm{Nu} \quad$ Nusselt number $(\ldots .$.

$\mathrm{P} \quad$ Mean pressure $(\mathrm{Pa})$

Pr Prandtl number (...)

Q Heat flux $\left(\mathrm{W} / \mathrm{m}^{2}\right)$

Re Reynolds number (...)

$\mathrm{T} \quad$ Temperature $(\mathrm{K})$

$u_{i} \quad$ Velocity vector $(\mathrm{m} / \mathrm{s})$

$\mathrm{u}^{\prime} \quad$ Root-mean-square of the turbulent velocity fluctuations

$\mathrm{x}, \mathrm{y}, \mathrm{z}$ Coordinates Greek Symbols

$\mu \quad$ Fluid dynamic viscosity $(\mathrm{Pa} \cdot \mathrm{s})$

$\rho \quad$ Fluid density $\left(\mathrm{kg} / \mathrm{m}^{3}\right)$

$\varphi \quad$ Volume fraction of nanoparticle Subscript

av Averaged

bf Base fluid

b Bulk

f $\quad$ Fluid

nf Nanofluids

p Particle

w Wall

$0 \quad$ Initial value 